\title{
COVID - 19 Vaccination in Patients with End Stage Kidney Disease. Early Results for an mRNA Vaccine in a Vulnerable Population
}

\author{
Noa Berar Yanay ${ }^{\star} \mathrm{MD}^{1}$, Zaher Armaly $\mathrm{MD}^{2,3}$ \\ ${ }^{1}$ Department of Nephrology, Hillel Yaffe Medical Center, Hadera, Israel \\ ${ }^{2}$ Department of Nephrology and hypertension, Nazareth Hospital, EMMS, Nazareth \\ ${ }^{3}$ Azrieli Faculty of Medicine in Safed, Safed, Israel
}

\begin{abstract}
Asian Journal of Complementary and Alternative Medicine. Volume 09 Issue 2
\end{abstract}
Published on: 17/06/2021

*Author for Correspondence: Noa Berar Yanay MD, Hillel Yaffe Medical Center, Hadera Israel 3810101; Email: noab@hy.health. gov.il; Tel: +972506246794; Fax: +97247744819

Cite this article as: Yanay NB, Armaly Z. COVID -19 Vaccination in Patients with End Stage Kidney Disease. Early Results for an mRNA Vaccine in a Vulnerable Population. Asian Journal of Complementary and Alternative Medicine, Vol 9(2), 49-53:2021.

\begin{abstract}
Patients with end stage kidney disease receiving dialysis treatment are at increased risk of COVID-19 infection. These patients have also higher rates of complications and mortality. The vulnerability may in part be explained by the profound changes in the immune system that are associated with impaired renal function. At the time of approval of the first vaccine for COVID-19, the BNT162b2 mRNA vaccine, there was no information on the efficacy and safety of the vaccine in dialysis patients. Preliminary reports on outcomes with the vaccine in the dialysis population have been published recently and the results are, in general, encouraging. However, these results indicate a lower response rate, a longer time to mount antibody response, lower antibody levels and possibly higher rate of COVID-19 breakthrough infection in the dialysis population. These results raise several questions that await further data to be reported. Meanwhile the dialysis patient's population may still need special attention. Lessons learnt in this special population may also be applicable for other vulnerable patient groups.
\end{abstract}

Keywords: Pfizer BioNTech COVID-19 vaccine, anti-spike antibody, end stage kidney disease, dialysis, immune-system

\section{COVID-19 IN PATIENTS WITH ADVANCED KIDNEY DISEASE}

Since the emergence of COVID-19 it was anticipated that patients with end stage kidney disease (ESKD) receiving dialysis treatment would be at high risk for contracting the disease, for complications and for mortality. These assumptions were based upon characteristics of this patient population: 1. End stage kidney disease is associated with alterations in the immune system. 2. Patients with ESKD often have complex comorbidities that are documented risk factors for adverse outcomes in patients with COVID-19. 3. In center dialysis treatment: patients must travel 3 times a week for dialysis treatment of an average 4-hours duration, and in many facilities, social distancing cannot be guaranteed [1]. Indeed, a higher rate of infection with COVID-19 was reported in the dialysis population when compared to the general population: The prevalence of infection reported from the French national REIN dialysis registry was between $1 \%-10 \%$ [2]. Another study from an urban center in the UK reported a prevalence of $19.6 \%$ infection in a large dialysis cohort [3]. Also, the mortality rate reported for these patients, in different countries was relatively high - between $16.2 \%$ to $31.7 \%$ - while at the same period the overall mortality rate from COVID -19 In Europe was 4\% and in Japan 5.3\% [4-9]. In the USA, excess mortality of $10.8-16.6$ cases per 1000 people in the first 6 months of the pandemic was reported for the dialysis population [10]. The higher mortality rate persisted even after adjustment for demographic characteristics and comorbidities [4]. The most common risk factors for mortality are older age, frailty, and additional comorbidities.

\section{Immune dysfunction in uremia}

The immune system is profoundly affected in advanced kidney disease.

ESKD is associated with high susceptibility to infections and reduced response to vaccinations [9,11-15]. Infection is the second most common cause of mortality in dialysis patients after cardiovascular disease, and the annual rate of sepsis is 100-300-fold higher in dialysis patients when compared to the general population [16]. Immune system disturbances in dialysis patients are complex. They are caused by uremia per se; by chronic kidney disease associated comorbidities 
and complications and by the dialysis treatment and other therapeutic interventions. Two connected but opposite aspects of the immune system are present in ESKD: activationresulting in persistent systemic inflammation, and dysfunctioncharacterized by reduced function and immunosuppression. While an enhanced inflammatory state is predominately associated with cardiovascular morbidity and excess mortality, the immune dysfunction is associated with high susceptibility to infections and altered response to vaccination [15-17]. Immune defense against infections depends on integrity and cooperation of the innate and adaptive immune systems. The innate immune system response involves pathogen-associated molecular patterns that are non-pathogen-specific. These include: 1. Secreted opsonins that bind to the bacterial wall and lead to activation of the complement system. 2. Receptors on phagocytic cells, involved in pathogen clearance by endocytosis, in MHC-II associated antigen presentation and in the activation of $\mathrm{T}$ cells. 3 . Activation of signal transduction pathways that enhance the inflammatory and immune response and activation of the adaptive immune response [12,14]. The adaptive immune system mounts an antigen and pathogen specific response through increased activation of specific $\mathrm{T}$ (killer and helper $\mathrm{T}$ cell populations) and B lymphocytes. The adaptive immune system is also responsible for immunological memory. These pathways are profoundly altered in ESKD. Some of these alterations include:

Decreased activity of monocytes that is associated with decreased activation of B and T lymphocytes [18]; Decreased phagocytic activity and killing capability of polymorphonuclear cells. This impairment is partially reversible after hemodialysis treatment [19]; Impaired terminal differentiation and maturation of monocyte derived dendritic cells, and reduced $\mathrm{T}$ cell proliferation in response to recall antigens. This impairment is independent on dialysis treatment [20]; Reduced CD4+/CD8+ T-lymphocyte ratio, reduced central memory T lymphocyte subpopulation and increased apopotosis [21] and B cell lymphopenia $[22,23]$.

Because of the reduced response to vaccinations, there are specific recommended dose regimens for ESKD patients for some common vaccinations. An example is the Hepatitis B virus (HBV) vaccination regimen: Patients on hemodialysis have low response to $\mathrm{HBV}$ vaccine with a seroconversion rate between $50 \%-70 \%$ following the standard vaccination regimen. Therefore, the recommended regimen for this population consists of a double dose of each injection and an additional (fourth) injection [24].

\section{Approval of mRNA COVID-19 vaccines}

On December 2020, less than a year after the SARS-COV-2 pandemic was declared by the WHO, the first emergency use authorization for the COVID-19 vaccine was granted by the FDA first to the Pfizer BiONTech BNT162b2 and few days later to the Moderna mRNA 1273 vaccine [23-26]. The authorization was based on results of phase 3 clinical trial results. [27,28] The rollout of the vaccines and ongoing worldwide vaccination efforts represent a huge and possibly definitive step in the global battle against the pandemic. This was the first time mRNA vaccines had been approved. Both Pfizer BioNTech and the Moderna phase 3 pivotal clinical trials did not include some special populations such as children, pregnant women, people with severe clinical conditions like people with an organ transplant, people with malignancies or people with advanced/end stage kidney disease. In the Pfizer BioNTech phase 3 clinical trial patients with stable chronic conditions were included, among them $256(0.7 \%$ of the trial population) patients with renal disease. Their chronic kidney disease stage was not mentioned. In the Moderna phase 3 clinical trial, there is no data on patients with kidney disease [27-29]. Clinical trials on the immunogenicity of COVID-19 vaccines in the dialysis population are ongoing and preliminary results are already available.

\section{The response to the COVID-19 vaccine in the dialysis population; the experience with BNT162b2 mRNA vaccine}

In a series of reports on nearly 500 dialysis patients who were vaccinated with the BNT162b2 mRNA vaccine, there were 3 main findings: 1 . The response rate after completion of 2 doses of the BNT162b2 vaccine was found to be lower. 2.The development of the humoral response was slower and 3. The anti-spike antibody level was lower when compared to the general population. [30-35], (table 1.). In these clinical trials there were no reports of any safety signal for the dialysis population.

1. Response rate following vaccination: The reported anti-Spike antibody response rate in dialysis patients was between $80 \%-96 \%$, as compared to a response rate of $100 \%$ in 227 people in control groups [32,35]. Studies in other patients' populations that are immunocompromised or immunosuppressed have yielded similar results the rate of response in patients with malignant conditions is between $60-95 \%$ [36]. The response rate reported in organ transplanted patients is between $22 \%$ - $54 \%$ [37-40].

2. The development of antibody response through the vaccination process may be slower in the dialysis population. In a study that evaluated the antibody response to vaccination in dialysis patients with and without previous COVID-19 infection, the response rate after the first dose of the BNT162b2 vaccine in patients with no previous infection was $18 \%$ [33]. Another study evaluated the initial response rate after the first vaccine 
Table 1: summary of clinical trials on antibody response to the BNT162b2 vaccine in dialysis patients

\begin{tabular}{|c|c|c|c|c|}
\hline $\begin{array}{l}\text { Author } \\
\text { (Reference) }\end{array}$ & $\begin{array}{l}\text { Patient } \\
\text { population \& } \\
\text { Control group }\end{array}$ & $\begin{array}{l}\text { Vaccine type } \\
\text { \& number of } \\
\text { doses }\end{array}$ & $\begin{array}{l}\text { Outcome } \\
\text { measure }\end{array}$ & Results \\
\hline $\begin{array}{l}\text { Jahn } \\
(31)\end{array}$ & $\begin{array}{l}\text { HD (72) } \\
\text { Control (16) }\end{array}$ & $\begin{array}{l}\text { BNT162b2 } \\
2 \text { doses }\end{array}$ & Anti -S IgG level & $\begin{array}{l}\text { HD-597AU/ml } \\
\text { C-800AU/ml } \uparrow \\
\text { For HD group antibody level negatively correlate with age } \dagger\end{array}$ \\
\hline $\begin{array}{l}\text { Grupper } \\
(32)\end{array}$ & $\begin{array}{l}\text { HD (56) } \\
\text { Control (95) }\end{array}$ & $\begin{array}{l}\text { BNT162b2 } \\
2 \text { doses }\end{array}$ & $\begin{array}{l}\text { Anti -S IgG response rate } \\
\text { Anti -S IgG level }\end{array}$ & $\begin{array}{l}\text { HD-96\% response } \\
\mathrm{HD}-2900 \mathrm{AU} / \mathrm{ml} \\
\mathrm{C}-100 \% \text { response } \dagger \\
\mathrm{C}-7401 \mathrm{AU} / \mathrm{ml} \uparrow \\
\text { Lower } \mathrm{Ab} \text { levels in older patients HD \& C }\end{array}$ \\
\hline $\begin{array}{l}\text { Agur } \\
(30)\end{array}$ & $\begin{array}{l}\mathrm{HD}(122) \\
\mathrm{PD}(23)\end{array}$ & $\begin{array}{l}\text { BNT162b2 } \\
2 \text { doses }\end{array}$ & Anti -S IgG response rate & $\begin{array}{l}\text { HD- } 93.4 \% \text { response } \\
\text { PD-95.6\% response } \\
\text { Lower } \mathrm{Ab} \text { levels in older and in patients with low albumin level }\end{array}$ \\
\hline $\begin{array}{l}\text { Attias } \\
(31)\end{array}$ & HD (64) & $\begin{array}{l}\text { BNT162b2 } \\
1 \& 2 \text { doses }\end{array}$ & Anti -S IgG response rate & $\begin{array}{l}\text { HD- } 18 \% \text { response after first vaccine } \\
\text { HD- } 80 \% \text { response after second vaccine } \\
\text { Lower Ab level in older patients: } \\
75 \% \text { response for }>70 \text { years }\end{array}$ \\
\hline $\begin{array}{l}\text { Berar Yanay } \\
(32)\end{array}$ & $\begin{array}{l}\mathrm{HD}(127) \\
\mathrm{PD}(33) \\
\text { Control (132) }\end{array}$ & $\begin{array}{l}\text { BNT162b2 } \\
2 \text { doses }\end{array}$ & $\begin{array}{l}\text { Anti -S IgG response rate } \\
\text { Anti-S IgG level } \\
\% \text { new COVID-19 infection }\end{array}$ & $\begin{array}{l}\text { HD+PD- 90\% response } \\
\text { HD+PD Median antibody level 116AU/ml } \\
\text { Lower Ab in older patients } \\
\text { HD-3.75\% COVID-19 infection post complete vaccination } \\
\text { C-100\% response } \dagger \\
\text { C- Median antibody level 176.5AU/ml } \uparrow \\
\text { C-no cases of infection post vaccination } \dagger\end{array}$ \\
\hline
\end{tabular}

HD- hemodialysis; PD- peritoneal dialysis; C control group; BNT162b2- Pfizer BioNTec 162b2 mRNA COVID-19 vaccine; anti-S IgGanti-spike protein antibody; AU- arbitrary units.

$\dagger-\mathrm{P}<0.05$

dose in dialysis patients and reported a response rate of $35 \%$ [41], while in a study that evaluated the response rate to vaccination with the $\mathrm{BNT} 162 \mathrm{~b} 2$ vaccine in a cohort of health care workers, the response rate was 95.5\% 14 days after the first dose [42]. Suggestions to delay or skip a second dose of the vaccine have been proposed $[43,44]$, but this strategy may not be appropriate for dialysis patients and other patient groups with lower and/or slower antibody response to vaccination.

3. The level of anti-Spike antibodies is consistently and significantly lower in the dialysis population when compared with a control group [ 31,32,35] The most common factor associated with a low antibody titer was older age. Lower albumin level lower lymphocyte count and BMI above $30 \mathrm{Kg} / \mathrm{m}^{2}$ were also associated with lower antibody level [32,33]. The dialysis modality (hemodialysis versus peritoneal dialysis) and the dialysis vintage (time since the start of dialysis) were not associated with anti-spike antibody levels
[33,34].Currently, there is no cut off level of anti-spike antibody that is defined as fully protective. It is possible that lower level could be associated with breakthrough infection. One study reported on 6 out of $160(3.75 \%)$ dialysis patients who developed a breakthrough COVID-19 infection more than 7 days after the second vaccine dose, as compared to 0 cases in the control group (132 people). Patients who developed a new infection had an anti-spike antibody level in the lowest quartile in the dialysis group [35]. These results imply a possible association between a low antibody level and the risk for COVID-19 breakthrough infection. The impact of a booster dose or doses of the vaccine on antispike antibody levels is yet unknown. It is possible that for dialysis patients an extended vaccination regimen will be advised, like the recommendations for other vaccines in this unique population [24].

More data is needed to address some important remaining questions: 
1. What is the response of dialysis patients to other COVID-19 vaccines?

2. Is there a need for monitoring antibody levels?

3. Should we give booster dose(s)to some or to all the patients?

4. If so, what would be the cut level for a booster dose?

\section{CONCLUSION}

As COVID-19 vaccination efforts are ongoing worldwide, preliminary reports on the efficacy and safety of the mRNA BNT162b2 vaccine in special vulnerable populations appear. For the dialysis population - results of these reports show overall high levels of efficacy and safety. However, this population does have a particular response pattern to vaccination; a lower response rate, a slower response, lower antibody titers post-vaccination and possibly further susceptibility for breakthrough COVID-19 infection. Some important questions regarding dosing regimen and need for antibody level surveillance await further clinical trial results. In the meantime, attention should be focused on maintaining some of the recommendations for social distancing and other precaution measures for further protection of dialysis patients even after vaccination is completed.

\section{REFERENCES}

1. Hsu CM, Weiner DE (2020) COVID-19 in dialysis patients: outlasting and outsmarting a pandemic.Kidney Int.98 (6):14021404

2. Couchoud C, Bayer F, Ayav C, Bechade C, et al. (2020) Low incidence of SARS-COV-2, risk factors of mortality and the course of illness in the French national cohort of dialysis patients. Kidney Int. 98 (6): 1519-1529

3. Corbet RW, Blakely S, Nitsch D, Loucaidou M, et al. (2020) Epidemiology of COVID-19 in an urban dialysis center. J Am Soc Nephrol. 31:1815-1823

4. Ng JH, Hirsch JS, Wanchoo R, Sachdeva M, et al. (2020) outcomes of patients with end-stage kidney disease hospitalized with COVID-19. Kidney International. 98:1530-1539

5. Hilbrand LB, Duivenvoorden R, Vart P, Franssen CFM. et al. (2020) COVID-19 related mortality in kidney transplant and dialysis patients: results of the ERACODA collaboration. Nephrol.Dial.Transplant. 35:1973-1983

6. Jager KJ, Kramer A, Chesnaye NC, Couchoud C, et al. (2020) Results from the ERA-EDTA Registry indicate a high mortality due to COVID-19 in dialysis patients and kidney transplant recipients across Europe. Kidney Int.98(6):1540-1548.

7. Aydin Bahat K, Parmaksiz E, Sert S (2020) The clinical characteristics and course of COVID-19 in hemodialysis patients. Hemodial Int.24(4):534-540.

8. Goicoechea M, Sánchez Cámara LA, Macías N, Munoz de Morales A, et -al. (2020) COVID-19: clinical course and outcomes of 36 hemodialysis patients in Spain. Kidney Int.98(1):27-34
9. Kikuchi K, Nangaku M, Ryuzaki M, Yamakawa T, et al. (2020) COVID-19 of dialysis patients in Japan:current status an guidance on preventive measures. Therapeutic Dialysis and Apheresis. 24(4) :361-365

10. Ziemba R, Campbell KN, Yang TH, Schaffer SE, et al. (2021) Excess death estimates in patients with end stage renal diseaseUnited States February-August 2020. Centers for Disease Control MMWR.

11. Vaziri ND, Pahl MV, Crum A, Norris K. (2012) Effect of uremia on structure and function of immune system. J Ren Nutr.22(1):149156

12. Kato S, Chimielewski M, Honda H, Pecoits-Filho R, et al. (2008) Aspects of immune dysfunction in End-stage renal disease. Clin $J$ Am Soc Nephrol 3:1526-1533.

13. Elefteriadis T, Antoniadi G, Liakopoulos V, Kartsios C, et al. (2007) Disturbances of acquired immunity in hemodialysis patients. Semin Dial. 20:440-451

14. Cohen G (2020) Immune dysfunction in Uremia 2020. Toxins,12, 439; doi:10.3390/toxins 12070439

15. Kurts C, Panzer U, Anders HJ, Rees AJ (2013) The immune system and kidney disease: basic concepts and clinical implications. Nat Rev Immunol. 13(10):738-53.

16. Sarnak MJ, Jaber BL (2000) Mortality caused by sepsis in patients with end-stage renal disease compared with the general population. Kidney Int. 58:1758-64.

17. Cozzolino M, Mangano M, Stucchi A, Ciceri P, et al. (2018) Cardiovascular disease in dialysis patients Nephrol Dial Transplant.33: iii28-iii34

18. Girndt M, Sester M, Sester U, Kaul H, et al. (2001) Molecular aspects of T-and B -cell function in uremia. Kidney Int.78: s206-s208

19. Anding K, Gross P, Rost JM, Allgaier D, et al. (2003) The influence of uremia and hemodialysis on neutrophil phagocytosis and antimicrobial killing. Nephrol. Dial. Transplant; 18:20672073

20. Verkade MA, van Druningen CJ, Vaessen LMB, Hesselink DA, et al. (2007) Functional impairment of monocyte-derived dendritic cells in patients with severe chronic kidney disease. Nephrol. Dial. Transplant. 22:128-138

21. Yoon J, Gollapudi S, Pahl M, Vaziri ND (2006) Naïve and central memory T-cell lymphopenia in end stage renal disease. Kidney Int. 70:371-376

22. Saad K, Elsayh KI, Zahran AM, Sobhy KM, et al. (2014) Lymphocyte populations and apoptosis of peripheral blood $B$ and T lymphocytes in children with end stage renal disease. Ren Fail. May;36(4):502-507.

23. Pahl MV, Gollapudi S, Sepassi L, Gollapudi P, et al. (2010) Effect of end-stage renal disease on B lymphocyte subpopulation, IL-7, BAFF and BAFF receptor expression.Nephrol. Dial. Transplant.25(1):205-212

24. Reddy S, Chituri C, Yee J. (2019) Vaccination in Chronic Kidney Disease. Adv Chronic Kidney Dis. 26:72-78 
25. Oliver SE, Gargano JW, Marin M, Wallace M, et al. (2020) The advisory committee on immunization practices' interim recommendation for use of Pfizer-BioNTech COVID-19 vaccineUnited States. MMWR 2020;69 (50):1922-1924

26. Oliver SE, Gargano JW, Marin M, Wallace M, et al. (2020) The advisory committee on immunization practices' interim recommendation for use of Moderna COVID-19 vaccine-United States. MMWR 2021;69 (51-52):1653-1655

27. Polack FP, Thomas SJ, Kitchin N, Absalon J, et al. (2020) Safety and efficacy of the BNT162b2 mRNA Covid-19 vaccine. N Engl J Med; 383:2603-15

28. Baden LR, El Sahly HM, Essink B, Kotloff K, et al. (2021) COVE Study Group. Efficacy and Safety of the mRNA-1273 SARS-CoV-2 Vaccine. N Engl J Med. 4;384(5):403-416.

29. Glenn DA, Hegde A, Kotzen E, Walter EB, et al. (2021) Systematic Review of Safety and Efficacy of COVID-19 Vaccines in Patients with Kidney Disease. Kidney Int Rep. 6(5):14071410. doi: 10.1016/j.ekir.2021.02.011. Epub 2021 Feb 9. PMID: 33585728 ; PMCID: PMC7870446.

30. Ikizler TA, Coats P, Rovin BH, Ronco P. (2021) Immune response to SARS-COV-2 infection and vaccination in patients receiving kidney replacement therapy.Kidney International;99(6):1275-1279

31. Jahn M, Korth J, Dorsch O, Anastasiou OE, et al. (2021) Humoral response to SARS-COV-2 vaccination with BNT162b2 (Pfizer BioNTech) in patients on hemodialysis. Vaccines,9,360. https:// doi.org/10.3390/vaccines 9040360

32. Grupper A, Sharon N, Finn T, Cohen R, et al. (2021) Humoral response to the Pfizer BNT162b2 vaccine in patients undergoing maintenance hemodialysis. Clin J Am Soc Nephrol 16: https://doi. org/10.2215/CJN.03500321

33. Agur T, Ben-Dor N, Goldman S, Lichtenberg S, et al. (2021) Antibody response to $m R N A$ SARS-COV-2 vaccine among dialysis patients- a prospective cohort study. Nephrol Dial. Transplant. doi:10.1093/ndt/gfab155

34. Attias P, Sakhi H, Rieu P, Soorkia A, et al. (2021) Antibody response to the BNT162b2 vaccine in maintenance hemodialysis patients.Kidney International;99(6):1490-1492
35. Berar Yanay N, Freiman S, Shapira M, Wishahi S et al. (2021) Experience with SARS-COV-2 BNT162b2 mRNA vaccine in dialysis patients. Kidney International;99(6):1496-1498

36. Monin L, Laing AG, Muñoz-Ruiz M, McKenzie DR, et al. (2021) Safety and immunogenicity of one versus two doses of the COVID-19 vaccine BNT162b2 for patients with cancer: interim analysis of a prospective observational study. Lancet Oncol. : doi: 10.1016/S1470-2045(21)00213-8.

37. Korth J, Jahn M, Dorsch O, Anastasiou OE, et al. (2021) A. Impaired Humoral Response in Renal Transplant Recipients to SARS-CoV-2 Vaccination with BNT162b2 (Pfizer-BioNTech). Viruses. 13(5):756. doi: 10.3390/v13050756.

38. Boyarsky BJ, Werbel WA, Avery RK, et al. (2021) Antibody Response to 2-Dose SARS-CoV-2 mRNA Vaccine Series in Solid Organ Transplant Recipients. JAMA. 325(21):2204-2206. doi:10.1001/jama.2021.7489

39. Rabinowich L, Grupper A, Baruch R, Ben-Yehoyada M, et al. (2021) Low immunogenicity to SARS-CoV-2 vaccination among liver transplant recipients. J Hepatol. doi: 10.1016/j. jhep.2021.04.020

40. Itzhaki Ben Zadok O, Shaul AA, Ben-Avraham B, Yaari V, et al. (2021) Immunogenicity of the BNT162b2 mRNA vaccine in heart transplant recipients - a prospective cohort study. Eur J Heart Fail. doi: 10.1002/ejhf.2199. Epub ahead of print. PMID: 33963635.

41. Torreggiani M, Blanchi S, Fois A, Fessi H, et al. (2021) Neutralizing SARS-CoV-2 antibody response in dialysis patients after the first dose of the BNT162b2 mRNA COVID-19 vaccine: the war is far from being won Kidney Int. 99(6):1494-1496

42. Favresse J, Bayart JL, Mullier F, Dogné JM, et al. (2021) Early antibody response in healthcare professionals after two doses of SARS-CoV-2 mRNA vaccine (BNT162b2) . Clin Microbiol Infect; doi: 10.1016/j.cmi.2021.05.004

43. Romero-Brufau S, Chopra A, Ryu AJ, Gel E, et al. (2021) Public health impact of delaying second dose of BNT162b2 or $m R N A$ 1273 covid-19 vaccine: simulation agent-based modeling study. BMJ. 373:1087. doi: 10.1136/bmj. n1087.

44. Pimenta D, Yates C, Pagel C, Gurdasani D (2021) Delaying the second dose of covid-19 vaccines. BMJ. 18;372: 710. doi: 10.1136/bmj. n710. 